\title{
Malignant Pheochromocytoma with Liver Metastases: About A Case
}

Mounir Jamali ${ }^{1}$, Othmane El Houadfi ${ }^{2}$, Omar El Jendouzi ${ }^{3}$, Ahmed Ameur ${ }^{4}$, Mohamed Alami ${ }^{5}$ Reda Tariqi ${ }^{6}$

\author{
${ }^{1}$ Resident in the Urology Department of the Med V Military Hospital of Rabat, Rabat, Morocco \\ ${ }^{2}$ Resident in the Urology Department of the Med V Military Hospital of Rabat, Rabat, Morocco \\ ${ }^{3}$ Urologist in the Med V Military Hospital of Rabat, Rabat, Morocco \\ ${ }^{4}$ Uro-Nephrology Pole Leader of the Med V Military Hospital of Rabat, Rabat, Morocco \\ ${ }^{5} \mathrm{Head}$ of Urology Department of the Med V Military Hospital of Rabat, Rabat, Morocco \\ ${ }^{6}$ Resident in the Urology Department of IBN Sina University Hospital Center, Rabat, Morocco
}

DOI: $10.36347 /$ sjmcr.2021.v09i03.006

| Received: 22.02.2021 | Accepted: 03.03.2021 | Published: 08.03.2021

*Corresponding author: Mounir Jamali

\section{Abstract}

Pheochromocytomas are rare tumors, developed at the expense of the adrenal medulla and paraganglia. The excess of catecholamines secreted leads to clinical symptomatology. The diagnosis of malignancy is made only by the presence of metastases from organs devoid of chromaffin tissue or by the appearance of neoplastic recurrences. A 20-year-old woman was reported to have hypertensive crises with cerebral and ocular repercussions. A malignant pheochromocytoma of the left adrenal gland with hepatic metastases was diagnosed and the patient underwent left adrenalectomy with hepatic metastasectomy and surgical portal embolization in preparation for a subsequent right hepatectomy.

Keywords: Malignant pheochromocytoma; liver metastases; adrenalectomy; surgical portal embolization.

Copyright $\odot$ $(2021$ The Author(s): This is an open-access article distributed under the terms of the Creative Commons Attribution 4.0 International License (CC BY-NC 4.0) which permits unrestricted use, distribution, and reproduction in any medium for non-commercial use provided the original author and source are credited.

\section{INTRODUCTION}

Pheochromocytoma is a rare neuroendocrine tumor, developed at the expense of chromaffin cells of the sympathetic nervous system producing an excess of catecholamines. The adrenal pheochromocytoma accounts for $80 \%$ of all pheochromocytomas, it is most often unilateral, but in $10 \%$ of cases a bilateral localization is observed.

Malignancy is defined by the presence of chromaffin tissue in the vessels, neighbouring organs by contiguity, adjacent lymph nodes and distant metastatic sites and/or bone.

Symptoms are due to catecholamine overproduction or mass effect. The diagnosis is confirmed by elevated levels of methanephrine or normetanephrine in plasma or urine. Radiology helps locate the tumor and any local invasion or metastasis. All patients should have preoperative preparation with $\alpha$ blockers and/or other drugs to control hypertension, arrhythmia and volume expansion. Surgery is the definitive treatment. Follow-up should last a lifetime.

\section{Observation}

Mrs. M.C., 20 years old, history of neuraxitis with ophthalmologic sequelae. The patient presented episodes of headache with vertigo, jet vomiting and profuse sweating, which prompted her to consult the emergency room. Clinical examination revealed a blood pressure of $260 / 140 \mathrm{mmHg}$ with tachycardia at $180 \mathrm{~b} / \mathrm{min}$.

A thoraco-abdominal-pelvic CT scan was requested, which came back in favor of a malignant pheochromocytoma with multiple liver metastases. 
Mounir Jamali et al., Sch J Med Case Rep, Mar, 2021; 9(3): 216-220

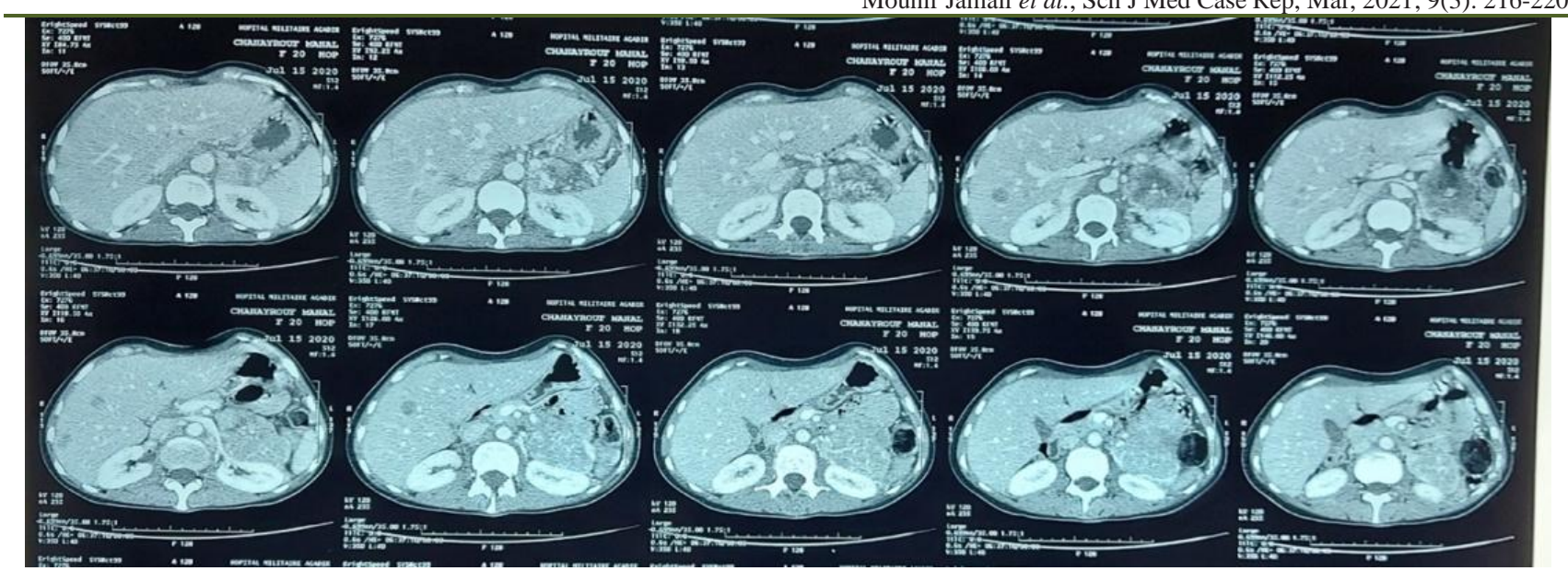

The biological workup revealed normal cortisolemia at 506.6nmol/1, normal urinary free cortisol at $30 \mathrm{nmol} / 24 \mathrm{~h}$, elevation of free metanephrines: Normetadrenaline $>32 \mathrm{nmol} / 1, \quad$ metadrenaline: $1.41 \mathrm{nmol} / 1,3$ OrthoMethyldopamine: $0.12 \mathrm{nmol} / 1$.

An elevation of urinary free metanephrines: Normetadrenaline > 4500nmol/24h, metadrenaline: 357nmol/24h, 3 OrthoMethyldopamine: 210nmol/24h.
Aldosteronemia collected supine was elevated: $2237 \mathrm{pmol} / \mathrm{l}$ with a normal aldosteronemia/renin ratio of 15.08. Active renin was also elevated at $82.30 \mathrm{pg} / \mathrm{ml}$.

A Uro-IRM was requested and concluded that there was a left adrenal lesion process invading the anterior border of the kidney and in contact with the renal pedicle, with liver metastases.

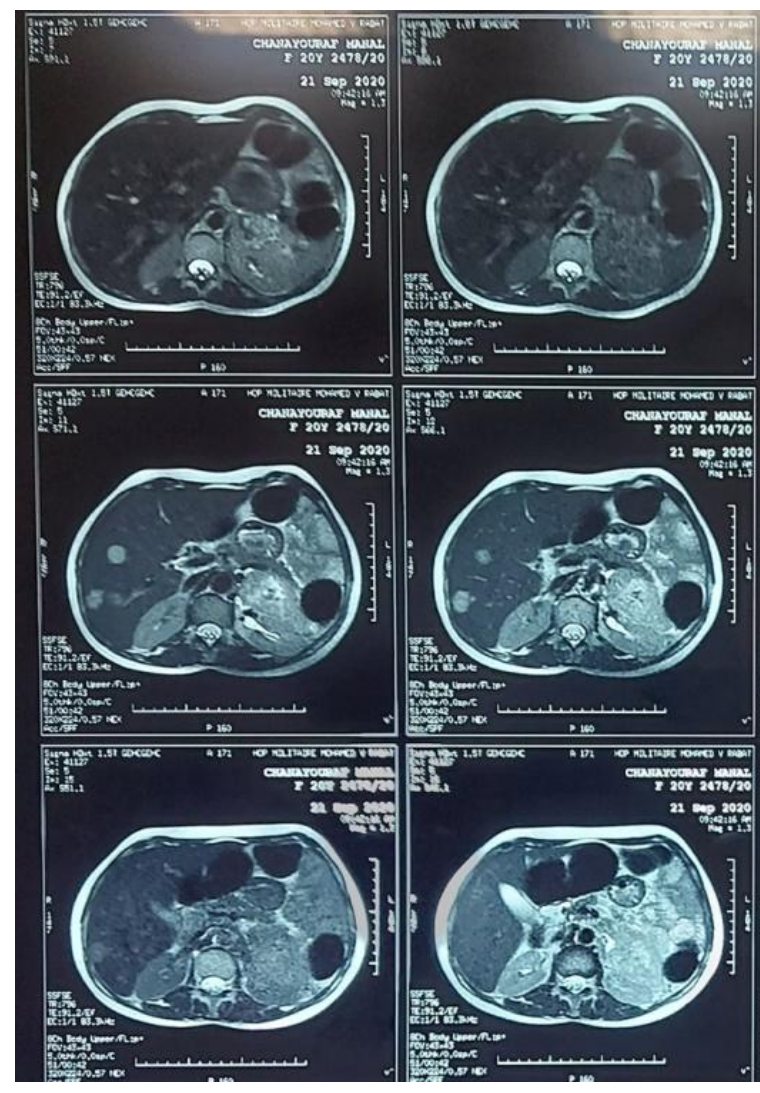

Cerebral MRI found some punctiform signal abnormalities of the supratentorial white matter with a rather vascular appearance.

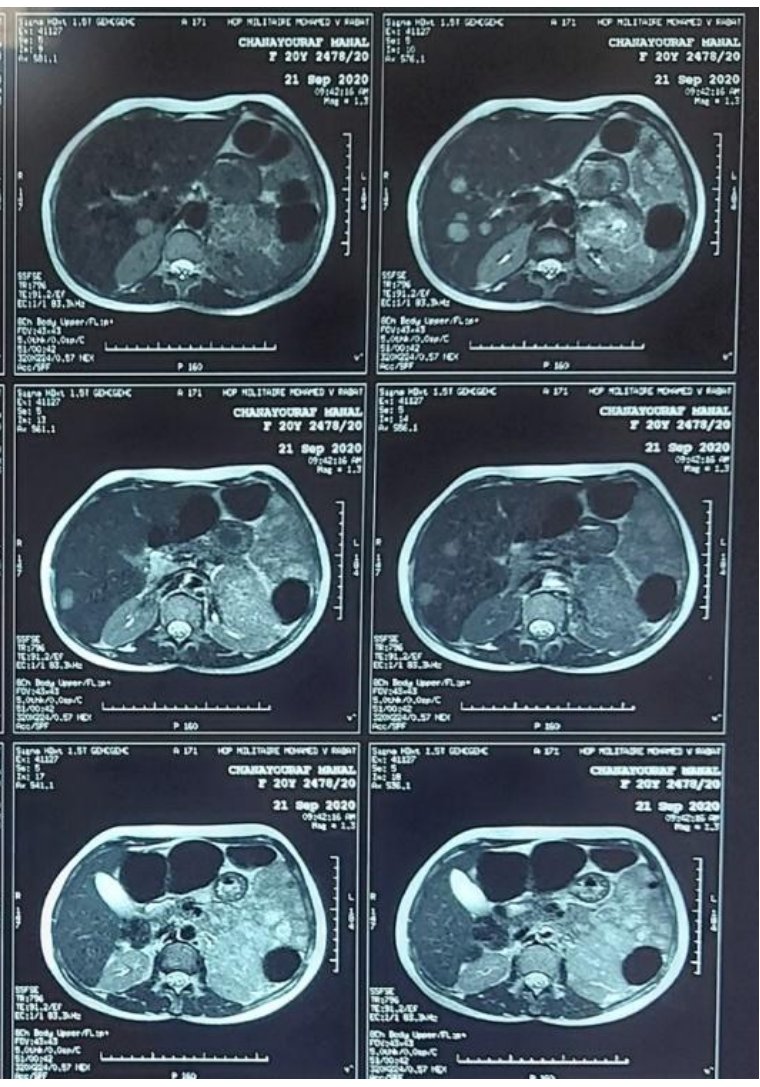

MIBG scintigraphy performed revealed hyperfixation over the left renal area persisting on images 24 and 48 hours after injection with hyperfixation of the dome and segments IV, VI, VII. 
Mounir Jamali et al., Sch J Med Case Rep, Mar, 2021; 9(3): 216-220

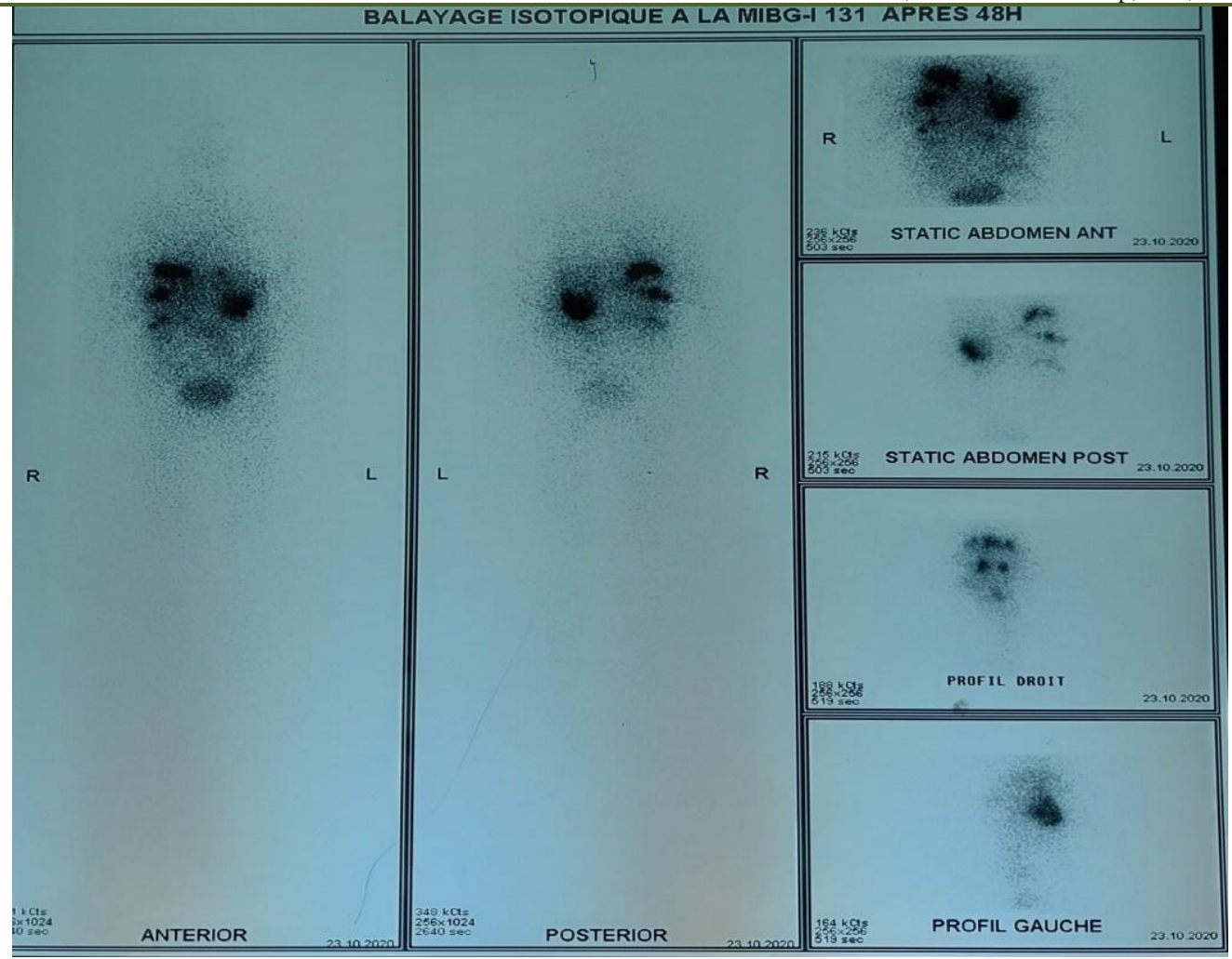

The PET Scan found a heterogeneous pathological hypermetabolic mass of the left adrenal area, poorly limited, pushing back the left kidney with discrete hypermetabolisms involving the dome and several hepatic segments and a bilateral and symmetrical hypermetabolism of the cervical, axillary, paravertebral and peri-renal fat along the sympathetic territories, linked to an activation of brown fat secondary to adrenergic stress.

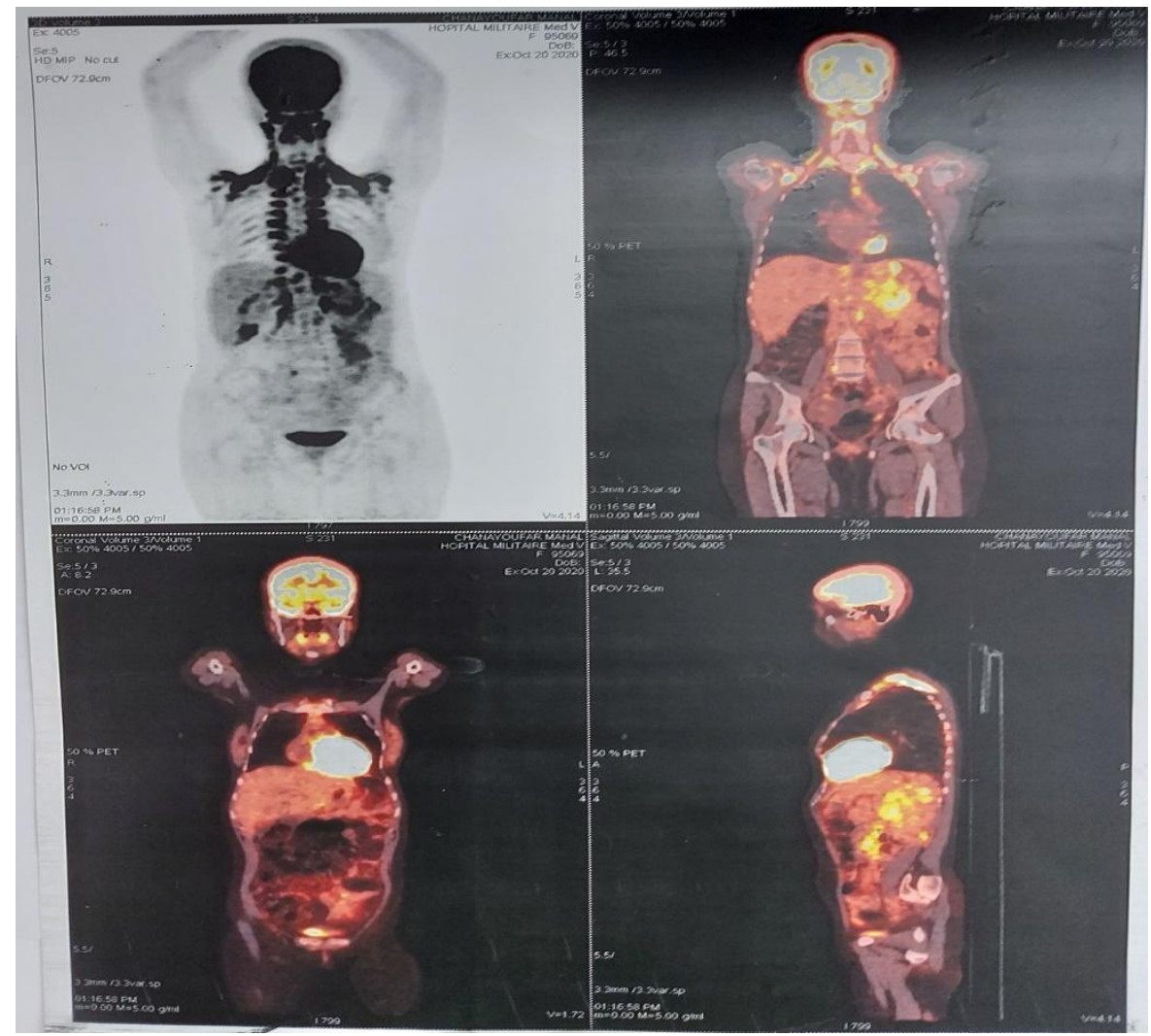


During her hospitalization, the patient presented a decrease in visual acuity and visual fog, the ophthalmologic examination concluded hypertensive retinopathy.

After cardiologic, endocrinologic and preanesthetic consultation, the patient was placed on alphaand beta-adrenergic blockade in preparation for surgery.
The patient benefited after extensive exploration from an open left adrenalectomy with resection of liver metastases, cholecystectomy and ligation of the right dividing branch of the portal vein to prepare the patient for a subsequent right hepatectomy. The procedure was completed without incident and blood pressure remained within desirable limits.

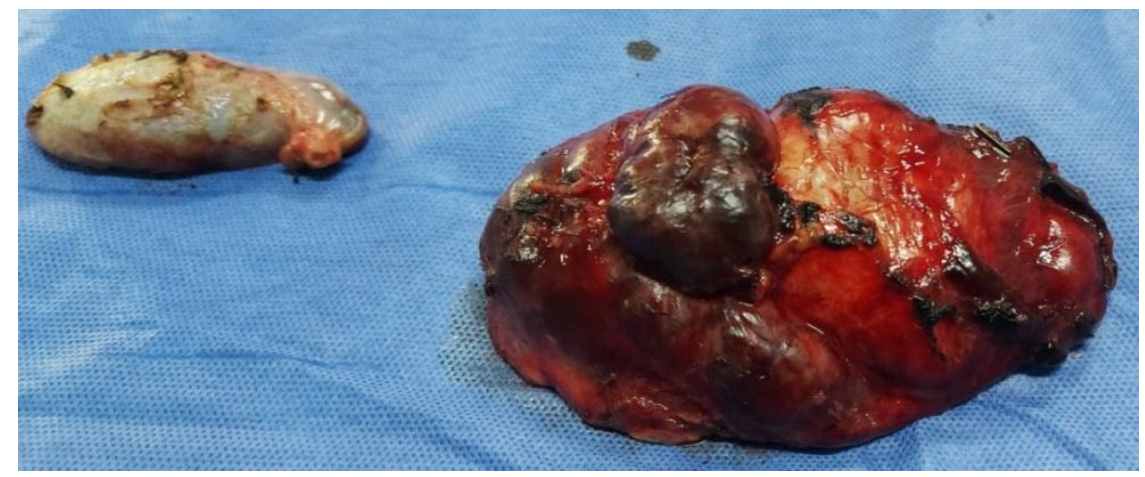

The postoperative period was marked by hypertensive peaks despite the treatment $\alpha$ and $\beta$ blocking and normalization of the blood pressure figures after a few days.

The result of the anatomopathological and immunohistochemical study came back in favor of a PASS pheochromocytoma score 4 for the adrenalectomy piece but also for the resected liver metastases.

\section{DisCUSSION}

Pheochromocytoma is a rare endocrine tumor derived from adrenal medullary chromaffin cells. It is generally accepted that $90 \%$ of cases occur sporadically, while $10 \%$ have a familial incidence, fitting within the framework of NEM types 2A and 2B, or associated with neurofibromatosis type 1 or Von Hippel-Lindau disease [1].

Malignancy occurs in about $10 \%$ of cases, with a height greater than $5 \mathrm{~cm}$, local invasion, internal necrosis, pleomorphism and nuclear hyperchromism being suspect features of malignancy, however, the only criterion used is the existence of secondary localizations devoid of chromaffin tissue [2].

Biological diagnosis is essentially based on the determination of plasma and urinary methoxylated derivatives, while the determination of plasma and urinary catecholamines has been abandoned as a firstline screening method. Plasma methoxytyramine is a predictive marker of pheochromocytoma malignancy [3].
A genetic study is recommended in cases of suspected genetic disease or in cases of bilateral pheochromocytomas and in patients under 45 years of age [4].

The radiological diagnosis is based on CT scan with a spontaneous density of malignant tumors greater than that for benign tumors, scintigraphy with MIBG labeled with iodine 123 has been supplanted by PET with 18F-DOPA especially for the detection of secondary localizations with a sensitivity close to $100 \%$ [5].

Pre-operative preparation is a crucial time, in order to avoid arrhythmia and hypertensive crisis on the operating table secondary to a mass release of catecholysis. mines during the induction of anesthesia or during the manipulation of the tumor by the surgeon. Blocking of $\alpha$ and $\beta$-adrenergic receptors is necessary.

The surgical management of a malignant pheochromocytoma with metastases that can be cured by total eradication requires adrenal surgery with focal treatment of metastases or metastasectomies. Chemotherapy, on the other hand, is aimed at nonoperable or non-resectable forms. In the case of liver metastases, preoperative transepatic portal embolization appears to be an excellent option for postoperative safety, and may prolong survival or the symptom-free period [6].

\section{CONCLUSION}

The malignant pheochromocytoma is a rare entity whose management requires multidisciplinary collaboration. The surgical risk is important even with adrenergic blockade but remains the pillar of therapeutic management. 
Mounir Jamali et al., Sch J Med Case Rep, Mar, 2021; 9(3): 216-220

\section{REFERENCES}

1. Bauters C, Wayerlot C. Les phéochromocytomes des néoplasies endocriniens multiples de type 2. Rev Franç Endocrinol Clin. 1998; 39, 1.

2. Andrade MO, Cunha VSD, Olivieira DC, Moraes OL, Lofrano-Porto A. What determines mortality in malignant pheochromocytoma? Report of a case with eighteen-year survival and review of the literature. Arch Endocrinol Metab. 2018; 62(2):264-269.

3. Eisenhofer G, Lenders JW, Siegert G, Bornstein SR, Friberg P, Milosevic D, Mannelli M, Linehan WM, Adams K, Timmers HJ, Pacak K. Plasma methoxytyramine: a novel biomarker of metastatic pheochromocytoma and paraganglioma in relation to established risk factors of tumour size, location and SDHB mutation status. European journal of cancer. 2012 Jul 1;48(11):1739-49.

4. Renard J, Clerici T, Licker M, Triponez F. Pheochromocytoma and abdominal paraganglioma. J Visc Surg. 2011 Dec;148(6):e409-16.

5. Taïeb D, Timmers HJ, Hindié E, Guillet BA, Neumann HP, Walz MK, Opocher G, De Herder WW, Boedeker CC, De Krijger RR, Chiti A. EANM 2012 guidelines for radionuclide imaging of phaeochromocytoma and paraganglioma. European journal of nuclear medicine and molecular imaging. 2012 Dec;39(12):1977-95.

6. Hori T, Yamagiwa K, Hayashi T, Yagi S, Iida T, Taniguchi K, Kawarada Y, Uemoto S. Malignant pheochromocytoma: Hepatectomy for liver metastases. World journal of gastrointestinal surgery. 2013 Nov 27;5(11):309-313. 